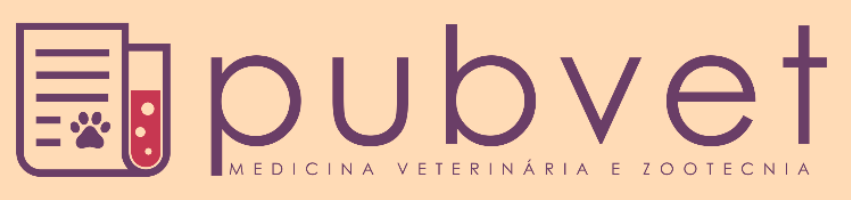

https://doi.org/10.31533/pubvet.v12n12a228.1-6

\title{
Isolamento de Aspergillus spp. e Nocardia sp. em processo inflamatório da glândula mamária de bovino leiteiro
}

\author{
Bruna Carolina Ulsenheimer ${ }^{*} \bullet$, Silvana Konageski Dalla $\operatorname{Rosa}^{2} \bullet$, Tatiana Melina \\ Caduri $^{30}$, Luciane Ribeiro Viana Martins ${ }^{4 \oplus}$ \\ 'Acadêmica do curso de Medicina Veterinária da Universidade Regional do Noroeste do Estado do Rio Grande do Sul \\ (UNIJUÍ), Departamento de Estudos Agrários, Íjuí - RS, Brasil. \\ ${ }^{2}$ Funcionária do Laboratório de Microbiologia Veterinária da UNIJUÍ, Departamento de Estudos Agrários, Íjuí - RS, Brasil. \\ ${ }^{3}$ Graduada do curso de Medicina Veterinária da UNIJUÍ, Departamento de Estudos Agrários, Íjuí - RS, Brasil. \\ ${ }^{4}$ Professora do curso de Medicina Veterinária, UNIJUÍ, Departamento de Estudos Agrários. Íjuí - RS, Brasil. \\ * Autor para correspondência, E-mail: bru.brunna@hotmail.com
}

\begin{abstract}
RESUMO. As mastites são um dos principais problemas enfrentados na pecuária leiteira, está se caracteriza pela inflamação da glândula mamária, com etiologia de origem bacteriana, fúngica, viral dentre outros. No presente estudo objetivou-se relatar a ocorrência de um caso de mastite bovina causada por Aspergillus spp. e Nocardia sp, em co-infecção na região Noroeste do Rio Grande do Sul. A amostra de leite foi analisada no laboratório de Microbiologia Veterinária da Unijuí semeada em ágar sangue ovino 5\% e ágar McConkey. Na análise visual do fungo, observou-se o crescimento de uma colônia branca, de aspecto aveludado, com aproximadamente $2 \mathrm{~cm}$ de diâmetro e com seu anverso de coloração esverdeada, ao exame microscópico, observou-se hifas ramificadas e septadas, vesícula, fiálides e conídios, compatíveis com características aspergilares, caracterizando o isolamento do Aspergillus spp. Na mesma amostra, observou-se visualmente a presença de colônias pequenas, de aspecto liso, coloração branco-opaco e firmemente aderidas ao ágar, com as seguintes características, colônias gram-positivas, filamentosas e ramificadas, com predominância de formatos bacilares, permitindo a identificação do gênero Nocardia sp. A partir deste caso nesta região, é possível enfatizar a grande importância de se realizar a identificação do agente causador da mastite, pois as mastites causadas por fungo, como o Aspergillus spp., concomitantemente com bactéria do gênero Nocardia sp., embora sejam de baixa ocorrência, causam diversos prejuízos econômicos, pela queda na quantidade e qualidade do leite produzido.
\end{abstract}

Palavras chave: bactéria, exame microbiológico, fungo, leite, mastite

\section{Isolation of Aspergillus spp. and Nocardia sp. in the inflammatory process of the mammary gland of bovine milk}

\begin{abstract}
The mastitis is one of the main problems faced in dairy farming, it is characterized by inflammation of the mammary gland, with etiology of bacterial, fungal and viral origin among others. The present study aimed to report the occurrence of a case of bovine mastitis caused by Aspergillus spp. and Nocardia sp, in a co-infection in the Northwest region of Rio Grande do Sul. The milk sample was analyzed in the laboratory of Unijuí Veterinary Microbiology seeded in 5\% sheep blood agar and McConkey agar. In the visual analysis of the fungus, the growth of a white, velvety-looking colony with approximately $2 \mathrm{~cm}$ in diameter and with its obverse of greenish coloration was observed, under microscopic examination, branched and septate hyphae, vesicle, phalidus and conidia, compatible with aspergillary characteristics, characterizing the isolation of
\end{abstract}


Aspergillus spp. In the same sample, the presence of small colonies, with a smooth appearance, white-opaque staining and firmly attached to the agar, with the following characteristics, gram-positive, filamentous and branched colonies, with predominance of bacillary formats, were observed visually. identification of the genus Nocardia sp. From this case in this region, it is possible to emphasize the great importance of identifying the causative agent of mastitis, since mastitis caused by fungi, such as Aspergillus spp., Concomitantly with bacteria of the genus Nocardia sp., Although they are low several economic losses, due to the decrease in the quantity and quality of the milk produced.

Keywords: bacterial, microbiological examination, fungus, milk, mastitis

\title{
Aislamiento de Aspergillus spp. y Nocardia sp. en proceso inflamatorio de la glándula mamaria de bovino lechero
}

\begin{abstract}
RESUMEN. Las mastitis son uno de los principales problemas enfrentados en la ganadería lechera, esta se caracteriza por la inflamación de la glándula mamaria, con etiología de origen bacteriano, fúngica, viral entre otros. En el presente estudio se objetivó relatar la ocurrencia de un caso de mastitis bovina causada por Aspergillus spp. y Nocardia sp, en coinfección en la región Noroeste de Rio Grande do Sul. La muestra de leche fue analizada en el laboratorio de Microbiología Veterinaria de la Unijuí sembrada en agar sangre ovina 5\% y agar McConkey. En el análisis visual del hongo, se observó el crecimiento de una colonia blanca, de aspecto aterciopelado, con aproximadamente $2 \mathrm{~cm}$ de diámetro y con su anverso de coloración verdosa, al examen microscópico, se observaron hifas ramificadas y septadas, vesícula, fálides y conidios, compatibles con características aspergilares, caracterizando el aislamiento del Aspergillus spp. En la misma muestra, se observó visualmente la presencia de colonias pequeñas, de aspecto liso, coloración blanco-opaco y firmemente adheridas al agar, con las siguientes características, colonias grampositivas, filamentosas y ramificadas, con predominio de formatos bacilares, identificación del género Nocardia sp. A partir de este caso en esta región, es posible enfatizar la gran importancia de realizar la identificación del agente causante de la mastitis, pues las mastitis causadas por hongo, como el Aspergillus spp., Concomitantemente con bacterias del género Nocardia sp., Aunque sean de baja, ocurren, causan diversos perjuicios económicos, por la caída en la cantidad y calidad de la leche producida.
\end{abstract}

Palabras clave: bacterias, examen microbiológico, hongo, leche, mastitis

\section{Introdução}

Vem se intensificando com o passar dos anos a ocorrência de doenças infecciosas no Brasil, causadas por agentes bacterianos, em consequência do seu clima tropical (Araujo et al. 2004). Dentre as doenças infecciosas que mais acometem o rebanho leiteiro, se destaca a mastite bovina, que representa um dos principais entraves para o setor leiteiro, devido aos prejuízos econômicos e sanitário que acarretam (Casanova et al. 2016; Costa et al. 2017).

Mastite é caracterizada por um processo inflamatório complexo da glândula mamária e, etiologicamente, trata-se de uma doença complexa de caráter multifatorial, envolvendo diversos patógenos, o ambiente e fatores inerentes ao animal, acarretando em modificação da composição do leite in natura (Moritz \& Moritz
2016). Segundo Tozzetti et al. (2008) 90\% das mastites são causadas por bactérias e em menor número, por fungos, algas e vírus.

Existem várias formas de diagnóstico da mastite bovina, como pela contagem de células somáticas (CCS) (Costa et al. 2017), Califórnia Mastitis Test (CMT) (Oliveira et al. 2004; Kapronezai et al. 2005), mas de acordo com Radostits et al. (2010), o exame microbiológico do leite é o método mais confiável.

A mastite causada por agentes como Nocardia sp., e Aspergillus spp., são de baixa ocorrência. Todavia, os microrganismos destes gêneros são facilmente encontrados no solo e na vegetação em deterioração, sendo considerados agentes oportunistas, que acometem indivíduos imunocomprometidos. O modo mais comum de causar infecção é por via aerógena, pela inalação 
do patógeno. No entanto, também pode ocorrer inoculação acidental destes agentes na glândula mamária, pela infusão de antibióticos por via intramamária com seringas contaminadas (Wattiaux 1995).

Este trabalho foi realizado para relatar um caso de diagnóstico laboratorial de mastite bovina causada por Nocardia sp. e Aspergillus spp., em co-infecção, ocorrido na região Noroeste do Estado do Rio Grande do Sul.

\section{Material e Métodos}

O diagnóstico foi realizado no Laboratório de Microbiologia Veterinária da UNIJUÍ, a partir da análise de uma amostra de leite mastítico bovino, recebida para exame microbiológico, proveniente da região Noroeste do Rio Grande do Sul, no período de maio de 2017. Conforme histórico, o animal apresentava mastite recorrente, com várias tentativas de tratamento sem sucesso.

A amostra foi identificada, e posteriormente semeada em meio específico, ágar sangue ovino $5 \%$ e ágar McConkey e incubadas a $36^{\circ} \mathrm{C}$ em estufa bacteriológica por um período de 48 horas.

Após o período de incubação, as placas foram analisadas e não se observou nenhum crescimento microbiológico, então foram mantidas por mais 24 horas na estufa bacteriológica. A partir deste período, observou-se o crescimento de uma colônia fúngica, com a suspeita de ser um microrganismo contaminante do processo de semeadura, por conseguinte, a amostra foi ressemeada. Novamente, após três dias da segunda semeadura, observou-se crescimento idêntico ao anterior, com fungo filamentoso, além de inúmeras colônias pequenas, brancas opacas. As colônias bacterianas e fúngicas cresceram na linha de cultivo, evidenciando serem provenientes da amostra de leite semeada.

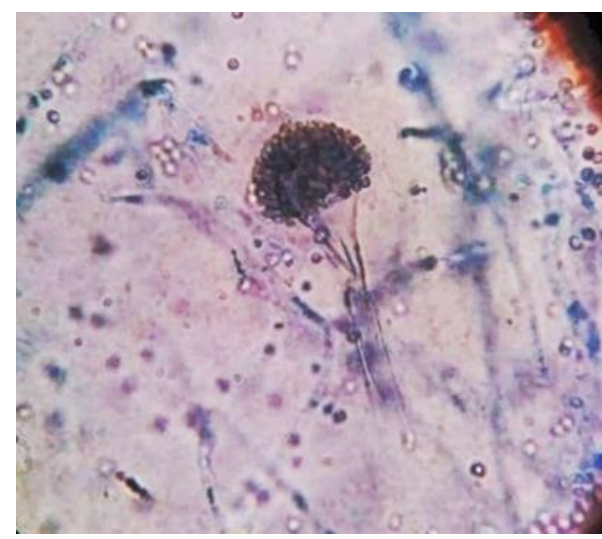

Figura 1. Colônia de Aspergillus spp. Em microscopia óptica. Objetiva 40X. Fonte: Arquivo pessoal.
Logo após, procedeu-se os demais passos para identificação do fungo e da bactéria. Iniciando pela observação visual das colônias crescidas nos meios de cultura e em seguida realizou-se esfregaços em lâminas, com coloração de Gram para a bactéria e azul de algodão para o fungo. Posteriormente, as lâminas foram examinadas em microscópio óptico, onde se observou as características morfológicas de cada microrganismo encontrado, então, o próximo passo foi transferir as amostras para meios contendo substâncias que evidenciam o metabolismo e a presença de enzimas, possibilitando assim a identificação do gênero dos microrganismos presentes na amostra de leite.

\section{Resultados}

$\mathrm{Na}$ análise visual do fungo, observou-se o crescimento de uma colônia branca, de aspecto aveludado, com aproximadamente $2 \mathrm{~cm}$ de diâmetro e com seu anverso de coloração esverdeada.

Neste caso, ao exame microscópico, observouse a presença de hifas ramificadas e septadas, vesícula, fiálides e conídios, compatíveis com características aspergilares, caracterizando a presença do Aspergillus spp., na amostra de leite mastítico, conforme figura 1.

Quanto à análise do crescimento de colônias bacterianas, observou-se visualmente a presença de colônias pequenas, de aspecto liso, coloração branca opaca e firmemente aderida ao ágar.

Ao exame microscópico, observaram-se as seguintes características: colônias gram-positivas, filamentosas e ramificadas, com predominância de formatos bacilares (Figura 2), permitindo a identificação do gênero Nocardia.

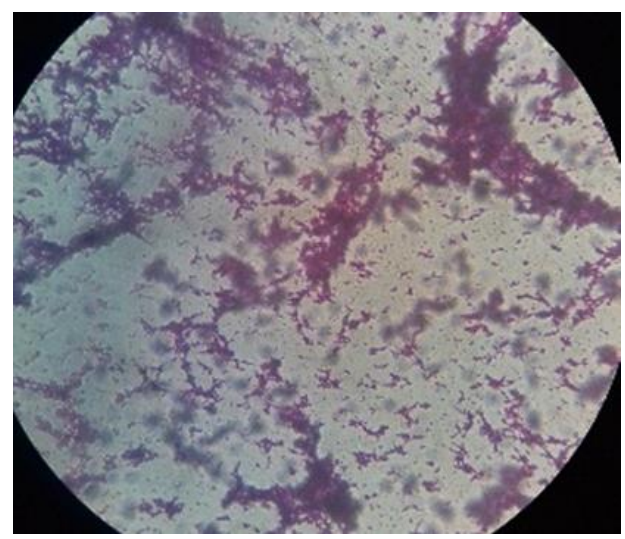

2. Colônias de Nocardia sp. Em microscópio óptico. Objetiva 100X. Fonte: Arquivo pessoal. 


\section{Discussão}

A metodologia tradicional de identificação de fungos filamentosos baseia-se, principalmente, nas características fenotípicas estruturais. ( $\underline{\mathrm{Cruz}}$ 2010). Sendo assim, o diagnóstico laboratorial de mastite causada por Aspergillus, baseia-se em sua morfologia colonial e aparência ao exame microscópico (Quinn et al. 2005).

A sintomatologia associada à mastite fúngica, causada pelo Aspergillus spp. inclui edema dos quartos mamários, aumento dos linfonodos supra mamários, queda na produção leiteira, alterações nas características organolépticas do leite. Já a apresentação clínica da mastite por Nocardia sp., se apresenta com diversos nódulos endurecidos, facilmente palpáveis, além de áreas de fibrose extensa nos quartos acometidos e diminuição na produção de leite (Wattiaux 1995).

Os patógenos fúngicos são cada vez mais descritos como causadores de mastite e a terapia antibacteriana intra-mamária facilita o aparecimento de mastite causada por leveduras. A maioria dos isolados pertencem aos gêneros Candida, Cryptococcus, Aspergillus e Trichosporum (Ruz-Perez et al. 2004). Segundo Melville et al. (2006) das 70 amostras de leite analisadas, visando a comparação da qualidade do leite quanto à presença e quantidade de fungos. Foram isolados, em diferentes percentagens, fungos filamentosos e leveduras, a Candida spp., Geotrichum spp., Rhodotorula spp., Trichosporon spp., Aureobasidium spp., Penicillium spp., Acremonium spp., Chrysosporium spp., Mucor spp. e Aspergillus spp. Sendo que não houve diferença estatisticamente significante entre a quantidade de unidades formadoras de colônias de fungos $/ \mathrm{ml}$, indicando que o nível de contaminação por fungos nas amostras foi similar na região de São Paulo. Desta forma, pode-se verificar que a ocorrência de mastites causadas por fungos, agentes passíveis de micoses oportunistas é comum em determinadas regiões.

Já Picoli et al. (2014) identificaram a presença de Escherichia coli (27,8\% das propriedades), Streptococcus agalactiae (6,2\%), S. dysgalactiae (37,2\%), S. uberis (16,8\%), Candida sp. $(15,7 \%)$, Aspergillus sp. (5,8\%), Trichosporum sp. (3,6\%) e Cryptococcus sp. (1,5\%) em propriedade na região sul do Rio Grande do Sul. Demonstrando que o Aspergillus é um agente que se faz presentes nas diferentes regiões do Rio Grande do Sul.
Na região Planalto Médio no Rio Grande do Sul, houve isolamento de 250 agentes bacterianos em 218 amostras $(90,8 \%)$ e 65 agentes leveduriformes em 39 amostras (16,2\%). Sendo que foram identificados 10 gêneros e 12 espécies de bactérias, sendo os gêneros Staphylococcus, Corynebacterium e Nocardia responsáveis por $88 \%$ dos isolados (Spanamberg et al. 2008). Costa et al. (1987) descreveram o isolamento de Nocardia asteroides em 24 amostras de leite mastítico bovino analisadas, em São Paulo. O que demonstra alta ocorrência da Nocardia na região de São Paulo, o que difere da ocorrência da Nocardia na região Noroeste do Estado do Rio Grande do Sul. Em estudo realizado por Martins et al. (2010) dos 92 animais que apresentaram mastite clínica e subclínica em pelo menos um quarto mamário, apenas uma das análises foi positiva para mastite clínica causada por Corynebacterium sp. + Nocardia sp concomitante, representando $4 \%$ dos agentes isolados. Demonstrando ser um microrganismo que ocorre geralmente em associação com outro microrganismo, podendo ser fúngico ou bacteriano. As técnicas de manejo mais precárias influenciam negativamente na qualidade microbiológica do leite, aumentando os riscos de ocorrência de agentes infecciosos e elevando as contagens de micro-organismos (Picoli et al. 2014). Para diminuir a ocorrência de mastite, devem ser seguidos alguns princípios básicos: diminuição da exposição dos tetos aos patógenos e o aumento da imunidade do animal (Casanova et al. 2016; Herry et al. 2017).

A aplicação destes conhecimentos relacionado à origem do microrganismo e a importância de cada microrganismo na patogênese da doença é de relevância para a realização da cultura e identificação dos agentes da mastite, bem como do antibiograma. Um diagnóstico correto é imprescindível para se aplicar medidas diferenciadas de controle e sugerir alterações a respeito do manejo do rebanho (Brito et al. 2014).

\section{Conclusão}

Neste trabalho, relatou-se um caso de diagnóstico laboratorial de mastite bovina causada por bactérias do gênero Nocardia sp. e Aspergillus spp., em co-infecção, ocorrido na região Noroeste do Rio Grande do Sul. A partir deste caso nesta região, é possível enfatizar a grande importância de se realizar a identificação do agente causador da mastite, pois as mastites causadas por fungo, como o Aspergillus spp., concomitantemente com 
bactéria do gênero Nocardia sp., embora sejam de baixa ocorrência, causam diversos prejuízos econômicos, como queda na quantidade e qualidade do leite produzido.

\section{Referências bibliográficas}

Araujo J.C.L.V., Lima E.O., Ceballos B.S.O., Kristerson R.L., Souza E.L. \& Santos Filho L. 2004. Ação antimicrobiana de óleos essenciais sobre microrganismos potencialmente causadores de infecções oportunistas. Revista de Patologia Tropical 33, 55-64.

Brito D.A.P., Silva I.d.S.O., Brito D.R.B. \& Costa F.N. 2014. Prevalência e etiologia da mastite em bovinos leiteiros da Ilha de São Luís, estado do Maranhão, Brasil. Brazilian Journal of Veterinary Medicine 36, 389-395.

Casanova V.P., Appio J., Kohl E., Michaelsen T.R., Paim D.S., Brunetto T.R., Pellegrini D.C.P., Bennemann P.E., Collet S.G. \& Girardini L.K. 2016. Bovine mastitis: prevalence and antimicrobial susceptibility profile and detection of genes associated with biofilm formation in Staphylococcus aureus. Semina: Ciências Agrárias 37, 1369-1378.

Costa E.O., Macedo M.M., Coutinho S.D.a., Castilho W., Teixeira C.M. \& Benesi J.F. (1987. Isolamento de Actinomicetales aeróbios do gênero Nocardia de processos infecciosos dos animais domésticos. Revista da Faculdade de Medicina Veterinária e Zootecnia da Universidade de São Paulo 24, 17-21.

Costa H.N., Molina L.R., Lage C.F.A., Malacco V.M.R., Facury Filho E.J. \& Carvalho A.Ú. 2017. Estimativa das perdas de produção leiteira em vacas mestiças Holandês x Zebu com mastite subclínica baseada em duas metodologias de análise. Arquivo Brasileiro de Medicina Veterinária e Zootecnia 69, 579-586.

Cruz L.C.H. 2010. Micologia veterinária. Revinter, Rio de Janeiro.

Herry V., Gitton C., Tabouret G., Répérant M., Forge L., Tasca C., Gilbert F.B., Guitton E., Barc C. \& Staub C. 2017. Local immunization impacts the response of dairy cows to Escherichia coli mastitis. Scientific Reports 7, 3441.

Kapronezai J., Melville P. \& Benites N.R. 2005. Análise microbiológica, teste de Tamis e California Mastitis Test realizados em amostras de leite de fêmeas bubalinas pertencentes a rebanhos do Estado de São Paulo. Arquivo do Instituto Biológico de São Paulo 72, 183-187.

Martins R.P., Silva J.A.G., Nakazato L., Dutra V. \& Almeida Filho E.S. 2010. Prevalência e etiologia infecciosa da mastite bovina na microrregião de Cuiabá-MT. Ciência Animal Brasileira 11, 181-187.

Melville P.A., Ruz-Peres M., Yokoia E. \& Benites N.R. 2006. Ocorrência de fungos em leite cru proveniente de tanques de refrigeração e latões de propriedades leiteiras, bem como de leite comercializado diretamente ao consumidor. Arquivos do Instituto Biológico 73, 295-301.

Moritz F. \& Moritz C.M.F. 2016. Resistência aos antimicrobianos em Staphylococcus spp. associados à mastite bovina. Revista de Ciência Veterinária e Saúde Pública 3, 132136.

Oliveira M.V.V., Mota R.A., Oliveira A.A.F., Meirelles F.S. \& Silva F.F. 2004. Utilização do Whiteside Modificado e California Mastitis Test no diagnóstico da mastite subclínica em búfalas e sua relação com o exame microbiológico. Ciência Animal 14, 39-45.

Picoli T., Zani J.L., Bandeira F., Roll V.F.B., Ribeiro M.E.R., Vargas G.D.Á., Hübner S.O., Lima M., Meireles M.C.A. \& Fischer G. 2014. Manejo de ordenha como fator de risco na ocorrência de microorganismos em leite cru. Semina: Ciências Agrárias 35, 2471-2480.

Quinn P.J., Markey B.K., Carter M.E., Donnelly W.J. \& Leonard F.C. 2005. Microbiologia veterinária e doenças infecciosas. Artmed, Porto Alegre.

Radostits O.M., Gay C.C., Blood D.C., Hinchcliff K.W. \& McKenzie R.A. 2010. Clínica Veterinária: um tratado de doenças dos bovinos, ovinos, suínos, caprinos e eqüinos. Guanabara Koogan, Rio de Janeiro.

Ruz-Perez M., Yokoya E., Passarelli D., Cantarino S.C., Benites N.R. \& Melville P.A. 2004. Pesquisa de fungos no leite de tanques de refrigeração de propriedades de exploração leiteira. Arquivo Instituto Biológico 71, 663665.

Spanamberg A., Wunder Junior E.A., Pereira D.I.B., Argenta J., Cavallini Sanches E.M., Valente P. \& Ferreiro L. 2008. Diversity of yeasts from bovine mastitis in Southern Brazil. 
Revista iberoamericana de micologia $25,154-$ 156.

Tozzetti D.S., Neto Bataier M.B., Almeida L.R. \& Piccinin A. 2008. Prevenção, controle e tratamento das mastites bovinas-revisão de literatura. Revista científica eletrônica de medicina veterinária $6,1-7$.

Wattiaux M.A. 1995. Mastitis: The disease and its transmission. Babcock Institute for
International Dairy Research and Development, Wisconsin.

Recebido: 15 setembro, 2018

Aprovado: 27 outubro, 2018.

Publicado: 26 dezembro, 2018.

Licenciamento: Este artigo é publicado na modalidade Acesso Aberto sob a licença Creative Commons Atribuição 4.0 (CC-BY 4.0), a qual permite uso irrestrito, distribuição, reprodução em qualquer meio, desde que o autor e a fonte sejam devidamente creditados. 